\title{
Relevant research article summaries
}

\author{
Nelson Fok \\ Adjunct Professor, Concordia University of Edmonton, Edmonton, AB, Canada
}

1. Adam, E.A., et al., 2016, Giardiasis Outbreaks in the US, 1971-2013, Epidemiology \& Infection, 144(13): 2790-2801.

Data on all giardiasis outbreaks reported to CDC were analyzed; $74.8 \%$ of the 242 outbreaks, affecting 41,000 persons, were traced to water, followed by food $(15.7 \%)$, person-toperson $(2.5 \%)$, and animal contact $(1.2 \%)$. Of waterborne outbreaks, $74.6 \%$ were associated with drinking water, followed by recreational water. Problems with water treatment, untreated groundwater, and distribution systems were identified most often during drinking water-associated outbreak investigations.

2. Blackstock, L.K.J., et al., 2017, Sweetened Swimming Pools and Hot Tubs, Environmental Science \& Technology Letters, 4(4): 149-153.

Researchers reported on the occurrence of acesulfame-K (ACE), a stable synthetic sweetener, in swimming pools and hot tubs. ACE is used in prepackaged foods and is not metabolized by humans, and it is completely absorbed and excreted exclusively in the urine. Analysis of more than 250 samples from 31 pools and tubs from two Canadian cities showed ACE in all samples. Concentrations ranged from 30 to $7,110 \mathrm{ng} / \mathrm{L}$, up to 570 -fold greater than in the input tap water. Using the average ACE level, researchers estimated the urine contributions as $30 \mathrm{~L}$ and $75 \mathrm{~L}$ for the two pools (110,000 and 220,000 US gallons, respectively).

3. Gharibvand, L., et al., 2017, The Association Between Ambient Fine Particulate Air Pollution and Lung Cancer Incidence: Results from the AHSMOG-2 Study, Environmental Health Perspectives, 125(3): 378-384.

Researchers assessed the association between $\mathrm{PM}_{2.5}$ and the incidence and mortality of lung cancer (LC) among those who had never smoked. The results identified increased risk estimates of LC for each $10 \mu \mathrm{g} / \mathrm{m}^{3}$ increment in ambient $\mathrm{PM}_{2.5}$ concentration. The estimate was higher among those who had resided longer at the enrollment address and those who spent $>1 \mathrm{hr} /$ day outdoors.

4. Ravel, A., et al., 2016, Non Food-Related Risk Factors of Campylobacteriosis in Canada: A Matched Case-Control Study, BMC Public Health, 16: 1016.

Campylobacteriosis is a prominent bacterial gastrointestinal infection agent. Its non-foodborne routes have been less documented and quantified. The study aimed to quantitatively explore the role of potential risk factors not directly associated with food for sporadic cases of $C$. jejni infection in Canada. This study found water was a major risk factor for campylobacteriosis in Canada.

5. Gandhi. N., et al., 2017, Are Fish Consumption Advisories for the Great Lakes Adequately Protective against Chemical Mixtures? Environmental Health Perspectives, 125(4): 586-593.

The Great Lakes are home to > 140 types of fish. The presence of toxic substances has resulted in the issuance of fish consumption advisories that are typically based on the most restrictive contaminant. Researchers simulated advisories using the most restrictive contamination and the multi-contamination additive effect. The results found half of the advisories currently issued are potentially not adequately protective based on the mixture of chemicals and their possible additive adverse effects.

6. Paulin, C., et al., 2017, An Assessment of Consumer Food Safety Handling Practices of Produce at Grocery Stores in Rhode Island, Food Protection Trends, 37(2): 99-106.

Produce contributed to more foodborne illnesses from 2004 to 2013 than any other food category. Researchers used direct observation and a smartphone application to observe food safety handling and hygiene practises of consumers shopping for produce at grocery stores in Rhode Island. A total of 80 individual consumers were observed at five grocery stores. The unsafe food safety handling practises of consumers included manipulating produce, putting produce back on the shelf, and tasting produce. Poor personal hygiene practices included touching hair, licking fingers to open a plastic bag, and touching ears, face or mouth, and glasses.

7. Guo, Y.C., et al., 2017, Analysis of Microcystins in Drinking Water by ELISA and LC/MS/MS, Journal of AWWA, 109(3): 13-19.

ELISA and liquid chromatography/tandem mass spectrometry were compared for analyzing microcystins in water. Results showed that ELISA-derived microcystins-LA concentrations were two to three times higher than the spike concentrations obtained using the kit-provided standards. LC/MS/MS results agreed with spike concentrations. Findings indicated that ELISA results, particularity in treated water, should be interpreted with caution because of the possibility of false-positives, relatively high variability, and differential detection of some variants. 
8. Luceron, C.O., et al., 2017, An Outbreak of Salmonella Typhimurium Associated with Playground Sand in a Preschool Setting-Madrid Spain, Sep-Oct 2016, MMWR, 66(9): 256-257.

A gastroenteritis outbreak affecting 24 students was identified. Samples of potable water and available prepared food were collected and no pathogens were detected. Samples of sand from five playground locations were collected and one sample collected on each date grew Salmonella of the same serotype. The results suggested an animal-human interface that facilitated transmission of the pathogens, and it highlights the necessity for enforcement of guidelines to prevent contamination in playground sand.

9. Gould, L.H., et al., 2017, Outbreaks of Disease Associated with Food Imported into the US, 1996-2014, Emerging Infectious Diseases, 23(3): 525-528.

Approximately $19 \%$ of food consumed in the US is imported, including $97 \%$ of fish and shellfish, $50 \%$ of fresh fruits, and $20 \%$ of fresh vegetables. The proportion of food that is imported has increased steadily over the past 20 years. This study found the number of reported outbreaks associated with imported foods, although small, has increased as an absolute number and in proportion to the total number of outbreaks in which the implicated food was identified and reported. Latin America and the Caribbean were the regions with the most outbreaks implicated, with Mexico being the most frequently implicated country ( 42 outbreaks). Other countries associated with $>10$ outbreaks were Indonesia (17) and Canada (11)

10. Van Ryswyk, K., et al., 2017, Metro Commuter Exposures to Particulate Air Pollution and PM ${ }_{2.5}$-Associated Elements in Three Canadian Cities: The Urban Transportation Exposure Study, Environmental Science \& Technology, 51: 5713-5720.

Air pollution exposure data were collected for the metro systems of Toronto, Montreal, and Vancouver. A microenvironmental exposure model was used to estimate the contribution of a 70-minute metro commute to daily mean exposure to $\mathrm{PM}_{2.5}$ elemental and mass concentrations. Time spent in the metro was estimated to contribute the majority of daily exposure to several metallic elements of $\mathrm{PM}_{2.5}$ and $21.2 \%, 11.3 \%$, and $11.5 \%$ of daily $\mathrm{PM}_{2.5}$ exposure in Toronto, Montreal, and Vancouver, respectively.

11. Stanley, F.K.T., et al., 2017, Comprehensive Survey of Household Radon Gas Levels and Risk Factors in Southern Alberta, Canadian Medical Association Journal, 5(1): E255-E264.

Between 2013 and 2016, 2,382 residential homes (2018 in Calgary and 364 in surrounding townships) were tested for radon for at least 90 days. The average indoor air radon level was $126 \mathrm{~Bq} / \mathrm{m}^{3} ; 47.6 \%$ of homes had levels of $100 \mathrm{~Bq} / \mathrm{m}^{3}$ or higher and $12.4 \%$ had levels of $200 \mathrm{~Bq} / \mathrm{m}^{3}$ or higher, exceeding Health Canada's guideline levels. Homes built in 1992 or later had radon levels $31.5 \%$ higher, on average, than older homes. Researchers attributed the higher levels to (1) insulation practices that reduce heat loss and often heat exchange; (2) an increase in home floor-plan size: larger concrete poured slabs resulting in greater shrinkage; and (3) more homes with vaulted ceilings that have greater thermal stack effects, generating more negative pressures at the basement level. Remediation can reduce radon levels to an average of $32.5 \mathrm{~Bq} / \mathrm{m}^{3}$.

12. Li, Z., et al., 2017, Sources, Health Effects and Control Strategies of Indoor Fine Particulate matter $\left(\boldsymbol{P M}_{2.5}\right): A$ Review, Science of Total Environment, 586: 610-622.

The sources of indoor $\mathrm{PM}_{2.5}$ consist of indoor origins and outdoor infiltration. Outdoor $\mathrm{PM}_{2.5}$ sources include crustal dust, vehicle emission, coal combustion, and some industry activities such as steel plants and the secondary particles produced by chemical reaction of primary particles in atmosphere from the outdoor sources. Due to air exchange between indoors and outdoors, the chemical component of indoor $\mathrm{PM}_{2.5}$ is associated with sources and components of outdoor $\mathrm{PM}_{2.5}{ }^{2.5}$ The principal indoor sources of $\mathrm{PM}_{2.5}$ are smoking, cooking, fuel combustion for heating, human activities, and burning incense. $\mathrm{PM}_{2.5}$ concentration in heating season was clearly higher than in non-heating season. Cooking was an important source of indoor particles, especially frying and grilling, releasing 10 times more $\mathrm{PM}_{2.5}$ than during a non-cooking period. Incense was a significant source of polycyclic aromatic hydrocarbon $(\mathrm{PAH})$, carbon monoxide, benzene, isoprene, $\mathrm{PM}_{2.5}$ and $\mathrm{PM}_{10}$.

13. Wright, J.M., et al., 2017, Disinfection By-Product Exposures and the Risk of Specific Cardiac Birth Defects, Environmental Health Perspectives, 125(2): 269-277.

Epidemiological studies suggested that women exposed to disinfection by-products (DBPs) have an increased risk of delivering babies with cardiovascular defects (CVDs). Researchers examined nine CVDs in relation to categorical DBP exposures and detected positive exposure-response relationships for DCAA and HAA5. Ventricular septal defects were associated with the highest bromoform, MBAA, and DBCM exposure categories.

14. Costard, S., et al., 2017, Outbreak-Related Disease Burden Associated with Consumption of Unpasteurized Cow's Milk and Cheese, US, 2009-2014, Emerging Infectious Diseases, 23(6): 957-964.

In the United States, outbreaks associated with dairy consumption caused, on average, 760 illnesses/year and 22 hospitalizations/ year, mostly from Salmonella spp. and Campylobacter spp. Unpasteurized milk, consumed by only $3.2 \%$ of the population, and cheese, consumed by only $1.6 \%$ of the population caused $96 \%$ of illnesses caused by contaminated dairy products. Unpasteurized dairy products caused 840 times more illnesses and 45 times more hospitalizations than pasteurized products.

15. Cohen, A.J., et al., 2017, Estimates and 25-Year Trends of the Global Burden of Disease Attributable to Ambient Air Pollution: An Analysis of Data from the Global Burden of Diseases Study 2015, The Lancet, 389: 1907-1918.

Ambient $\mathrm{PM}_{2.5}$ was the fifth-ranking mortality risk factor in 2015. Exposure to $\mathrm{PM}_{2.5}$ caused 4.2 million deaths and 
103.1 million disability-adjusted life-years (DALYs) in 2015, representing $7.6 \%$ of total global deaths and $4.2 \%$ of global DALYs, $59 \%$ of these in east and south Asia. Deaths attributable to ambient $\mathrm{PM}_{25}$ increased from 3.5 million in 1990 to 4.2 million in 2015. Exposure to ozone caused an additional 254,000 deaths and a loss of 4.2 million DALYs from chronic obstructive pulmonary disease in 2015. Ambient air pollution contributed substantially to the global burden of disease in 2015 due to population ageing, changes in non-communicable disease rates, and increasing air pollution in low-income and middleincome countries.

16. De Siqueira, E.C., et al., 2017, Does Cell Phone Use Increase the Chances of Parotid Gland Tumor Development? A Systematic Review and Meta-Analysis, Journal of Oral Pathology \& Medicine, online version.

A systematic literature search identified 37 articles, and three were included in a meta-analysis. The results found that cell phone use seems to be associated with greater odds (1.28 95\% CI:1.09-1.51) of developing a salivary gland tumor.
Results should be read with caution due to the limited number of studies available and their retrospective design.

\section{Santos, C., et al., 2017, Reported Adverse Health Effects in Children from Ingestion of Alcobol-Based Hand Sanitizers- US, 2011-2014, MMWR, 66(8): 223-226.}

In 2005, the annual rate of intentional alcohol hand sanitizer exposure was 0.68 per 1 million US residents. During 20052009 , the rate increased on average by $0.32 /$ million per year. During 2011-2014, a total of 70,669 hand sanitizer exposures in children aged $<12$ were reported. Overall, $91 \%$ exposures occurred in children aged $<5$ years and $9 \%$ in children aged 6-12. Among all children, ingestion accounted for approximately $95 \%$ of reported exposures. A higher percentage of older children (aged 6-12) had intentional exposures to alcohol hand sanitizers than to nonalcohol hand sanitizers. The findings suggested that older children might be deliberately misusing or abusing alcohol hand sanitizers. Exposures occurred more frequently during the winter months. This may be due to more ready access to sanitizers during flu season or the school year. 